\title{
CONFERÊNCIA
}

\section{A EDUCAÇÃO SUPERIOR E OS DESAFIOS DA PRÁTICA DOCENTE'}

\author{
Anselmo Alencar Colares²
}

\section{INTRODUÇÃO}

Certa vez li uma narrativa sobre uma empresa do ramo de calçados, a qual pretendia estabelecer uma filial em outra cidade e para lá enviou seu vendedor mais experiente para que pudesse ter um termômetro do potencial de negócios. Na bagagem um número limitado de produtos para uma primeira venda. Ao chegar ao local o vendedor mediante observação atenta ficou abalado e enviou mensagem solicitando que seu retorno fosse abreviado argumentando "aqui ninguém usa sapatos". Os dirigentes da empresa acolheram o pedido, porém, resolveram enviar um segundo emissário. Desta feita um jovem vendedor, sem a experiência do primeiro, todavia com o entusiasmo e a vontade de acertar que são típicos das pessoas determinadas. Este, ao chegar e também fazer a observação atenta, imediatamente enviou mensagem com o seguinte teor: "Mandem mais sapatos. Aqui ninguém usa!".

Uma mesma situação vista sob perspectivas diferentes. Um olhar "experiente" - colocada entre aspas por concordar com o entendimento de Larossa para o qual a experiência não pode ser confundida com o tempo. As vezes uma pessoa faz algo durante décadas, mas a experiência é mínima porque faz sempre da mesma forma irrefletida. Por outro lado, outro que faz

\footnotetext{
1 Texto adaptado do conteúdo da palestra ministrada na Universidade Federal do Oeste do Pará/Ufopa para docentes que ingressaram por Concurso Público em 2017, para trabalhar na UFOPA

2 Doutor e Pos-doutor em Educação pela Unicamp. Professor do Curso de Pedagogia e do Programa de Pos-graduação em educação da Ufopa. Líder do Grupo de Estudos e Pesquisas História, Sociedade e Educação no Brasil - HISTEDBR UFOPA. Vice-reitor da Ufopa (Gestão 2014-2018). E-mail: anselmo.colares@gmail.com
} 
a menos tempo, exercita a capacidade reflexiva e com isso reelabora o conhecimento sobre o que faz, ampliando o saber e, por conseguinte, a experiência.

Como estou me dirigindo a professores que acabam de ingressar na Ufopa, faço uma analogia com a narrativa acima e convido-os a se perguntarem sobre qual olhar lançam sobre esta instituição e sobre as pessoas para as quais vão estar "vendendo" seus produtos. Estou utilizando os termos mercadológicos apenas como ilustração, mas é claro que não considero a educação mercadoria e muito menos as pessoas como clientes, nem tampouco a instituição universidade como uma organização. Alias, sugiro a leitura de textos de Marilena Chaui nos quais ela aborda este tema com muita propriedade, fazendo a defesa da instituição e apontando todos os problemas decorrentes da crescente investida para que ela torne-se cada vez mais operacional, em detrimento do seu papel político e social enquanto instituição publica.

Organizei a fala para esta mesa-redonda na qual divido espaço com o colega professor doutor Luis Percival Leme Brito, abordando o conteúdo em tópicos na seguinte sequência: EXPECTATIVAS (mão dupla); AS IFES E A UFOPA (novos perfis); A AULA E O ENSINO SUPERIOR (possibilidades); TÓPICOS COMPLETOS (Objetivos e metas. Começo, meio e fim); LINGUAGEM (simples, sem ser simplista) e AVALIAÇÃO (formativa, explícita). Abordarei também os desafios da docência.

Ressalto, todavia, que em decorrência do tempo curto para a exposição (trinta minutos) e também de alguns pequenos desvios típicos da oralidade, o conteúdo do texto não mantem total fidedignidade com a fala, sendo que alguns aspectos aqui encontram-se melhor elaborados e outros foram mais ricamente exemplificados na exposição. O texto resulta de um compromisso que assumi de socializar, como forma de instigar a continuidade do debate, e possibilitar aos que não puderam acompanhar a mesa-redonda, elementos para refletirem sobre a educação superior e os desafios da prática docente. 
Desenvolverei a abordagem quase exclusivamente para o ensino, mas reconheço que os desafios colocam-se também para a extensão e a pesquisa, por serem os pilares que sustentam a universidade. E vão além, tendo em vista que em algum momento estamos na administração, seja na condição de coordenador de curso, dirigente de unidade ou na reitoria. A docência universitária é muito ampla e complexa. Mas poucos são os que chegam na universidade com a formação global que o seu exercício requer, incorporando o tripé constituinte de sua natureza: Ensino - Pesquisa Extensão ${ }^{3}$.

\section{A DOCÊNCIA UNIVERSITÁRIA}

Quanto ao primeiro item da exposição, que denominei EXPECTATIVAS (mão dupla), chamo a atenção para o fato de que na vida sempre criamos alguma ou algumas expectativas sobre algo que vamos fazer. Como professores, planejamos nossas aulas com vistas a alcançarmos determinados objetivos. Neles estão embutidos valores e concepções com as quais nos forjamos ao longo de nosso percurso formativo. Embora sujeitas a mudanças, são elas que orientam as nossas expectativas iniciais. Mas quando coloco a expressão mão dupla, chamo a atenção para que pensemos um pouco a respeito do que os estudantes estão a querer das

\footnotetext{
3 Como resultado de reflexões sobre a indissociabilidade ensino pesquisa e extensão não apenas como exigência constitucional para a Universidade, mas também na atividade docente, já escrito artigos, alguns em parceria com outros colegas. Alguns disponíveis na internet, tais como:

COLARES, A. A. O projeto pedagógico institucional (ppi) e a indissociabilidade ensinopesquisa-extensão. Revista Exitus v. 5, n. 1 (2015). Conferência proferida no fechamento da IV Jornada Acadêmica da Universidade Federal do Oeste do Pará (UFOPA), em 2015, que teve como tema central A INDISSOCIABILIDADE ENSINO, PESQUISA E EXTENSÃO nas universidades.

http://www.ufopa.edu.br/portaldeperiodicos/index.php/revistaexitus/article/view/79/79

COLARES, A. A., COLARES, M. L. I. S., GONÇALVES, T. O., LEÃO, J. P. P. O professorpesquisador-reflexivo: debate acerca da formação de sua prática. Revista Olhar de professor, Ponta Grossa, 14(1): 151-165, 2011.

http://www.revistas2.vepg.br/index.php/olhardeprofessor/article/viewFile/3490/2508

COLARES, A. A., COLARES, M. L. I. S., A docência na universidade: em defesa da indissociabilidade ensino, pesquisa e extensão. Apresentado em evento da Associação Nacional de Política e Administração da Educação (ANPAE).

http://www.anpae.org.br/iberolusobrasileiro2010/cdrom/13.pdf
} 
nossas aulas, da nossa postura enquanto professores. Por tratar-se de um caminho de mão dupla, temos um primeiro desafio. O de tomar os devidos cuidados para que não ocorram colisões frontais de resultados catastróficos. E de cuidar também para que não estejamos caminhando em velocidade incompatível com a via ou até mesmo na contra mão dos demais viajantes. Uma sugestão é realizarmos uma sondagem inicial. Nos dar a conhecer e também buscar conhecer os nossos estudantes é muito importante para que as expectativas sejam alinhadas, e por conseguinte, para que os objetivos sejam melhor elaborados com vistas a serem alcançados de forma exitosa para todos os envolvidos nesta relação de aprendizagem. Professor não apenas ensina. Também aprende.

As expectativas, por sua vez, estão profundamente relacionadas com o perfil das pessoas que compõem o ambiente no qual estamos. A Ufopa e as demais Instituições Federais de Ensino Superior (IFES), gradativamente estão mudando. Por conta de fatores internos e externos, estes últimos talvez em maior profusão. Setores majoritários da nossa população aos poucos vão conseguindo ter acesso, mas ainda estão longe de ter a garantia da permanência - por meio de ações efetivas - e menos ainda o sucesso, em termos de aprovação. A diversidade cada vez mais presente na universidade. E com tudo o que ela significa: aflorando as contradições, algumas vezes aprofundando e outras vezes quebrando resistências, enfim, produzindo uma nova realidade e exigindo outra compreensão sobre as IFES e que estas repensem a ação educativa e o compromisso com a cidadania.

Faz-se necessário, portanto, redimensionar a docência universitária. Tal perspectiva põe em evidência o uso de novas tecnologias, mas isso não basta, é preciso comprometimento coletivo e compromisso institucional com os demais fatores que favoreçam a realização de uma educação superior em sintonia com as necessidades de desenvolvimento profissional, e as exigências sociais de preparação para o exercício de uma cidadania alicerçada em princípios éticos de respeito à diversidade e de inclusão irrestrita. E neste sentido podemos afirmar que a formação do professor não 
se esgota nos cursos de formação inicial ou mesmo na pós-graduação stricto sensu, ela precisa ocorrer de forma permanente e continuada, em que a integração teoria e prática é basilar para a práxis transformadora.

A aula, seja presencial ou à distância, tem como propósito gerar aprendizagem nos alunos. E aprendizagem significa $O$ desenvolvimento integral da pessoa, em diversos aspectos, que incluem capacidades intelectuais, habilidades profissionais e desenvolvimento de atitudes e valores. Há uma relação quase indissociável entre o aprender e o ensinar. Como podemos notar nas palavras de Sousa $(2005$, p. 35),

Aprender e ensinar constituem duas actividades muito próximas da experiência de qualquer ser humano: aprendemos quando introduzimos alterações na nossa forma de pensar e de agir, e ensinamos quando partilhamos com o outro, ou em grupo, a nossa experiência e os saberes que vamos acumulando [...]

Como professores universitários, devemos repensar o conceito de aula. Esta atividade não pode ficar restrita ao que se passa em uma sala convencional de uma instituição que recebe o nome de faculdade, centro universitário ou universidade. A aula universitária pode estar presente em muitos outros espaços.

[...] Onde quer que possa haver uma aprendizagem significativa buscando atingir intencionalmente objetivos definidos, aí encontramos uma 'aula universitária'. Assim, tão importante quanto a sala de aula, onde se ministram aulas teóricas na universidade, e os laboratórios, onde se realizam as aulas práticas, são os demais locais onde, por exemplo, se realizam as atividades profissionais daquele estudante: empresas, fábricas, escolas, posto de saúde, hospital, fórum, escritórios de advocacia e de administração de empresas, casas de detenção, canteiro de obras, plantações, hortas, pomares, instituições públicas e particulares, laboratórios de informática, ambulatórios, bibliotecas, centros de informação, exploração da internet, congressos, seminários, simpósios nacionais e internacionais etc. (MASETTO, 2005, p. 89).

Alguns questionamentos apresentam-se como indispensáveis para nortear a reflexão sobre a atividade docente. O que os professores precisam saber para poder ensinar e para que seu ensino possa conduzir as 
aprendizagens dos alunos? Como os professores aprendem a ensinar? Como professores constroem conhecimentos sobre o ensino?

A propósito do entendimento do ato de ensinar necessariamente associado com a aprendizagem, vejamos a argumentação desenvolvida por um dos idealizadores da Escola Nova:

\begin{abstract}
Ensinar é como vender mercadorias. Ninguém vende, se ninguém compra. Seria ridículo um negociante que dissesse ter vendido muitos artigos, embora ninguém tivesse comprado nada. Mas haverá, talvez, professores que, sem cogitar do que aprenderam os alunos, julguem terem tido um bom dia de ensino. Existe a mesma exata equação entre ensinar e aprender que entre vender e comprar. 0 único meio de fazer que os alunos aprendam mais é ensinar verdadeiramente, mais e melhor (DEWEY, 1959, p. 43).
\end{abstract}

Estudos tais como os de Tardif (2001; 2002), Shulman (1986), Schön (2000), Perrenoud (2000), embora não conclusivos, têm contribuído para compreensões sobre o que o professor pensa e sobre como aprende a ser professor. Boa parte da pesquisa sobre os professores e sua formação tem-se desenvolvido, nas últimas décadas, a partir de estudos sobre o ensino e o currículo. Muito se ganhou com esse tipo de pesquisa, tendo como centro as ações dos professores e dos alunos em ambientes de sala de aula. Os resultados apontaram, entre outros aspectos, que o comportamento do professor poderia ser relacionado ao desempenho do aluno e que a escola poderia fazer diferença na aprendizagem dos alunos, até então entendido como quase que exclusivamente determinado pela classe social e outras características familiares e da vida atual e pregressa das crianças.

A compreensão da profissão docente exige a inclusão de outros processos analíticos. Entre eles, estabelece-se com destaque, a construção dos saberes e dos valores, responsáveis pela produção cotidiana do trabalho do professor. É certo que a docência sofre determinações do sistema e da sociedade, provocando processos de reprodução social. Mas é reconhecido, também, que os professores são sujeitos históricos, capazes de transformações, especialmente quando sentem-se protagonistas de seu fazer profissional. 
Além das pesquisas inicialmente centradas no ensino e no currículo, estudos sobre o 'pensamento do professor' e, posteriormente, também sobre o 'conhecimento do professor' passaram a ser desenvolvidos a partir dos anos 1980. Todavia, algumas destas pesquisas simplificaram as complexidades do ensino em sala de aula, e ignoraram um aspecto central: o conteúdo específico da disciplina que os professores lecionam.

Para Shulman a base de conhecimento para o ensino consiste de um corpo de compreensões, conhecimentos, habilidades e disposições que são necessários para que o professor possa propiciar processos de ensinar e de aprender, em diferentes áreas de conhecimento, níveis, contextos e modalidades de ensino. Essa base envolve conhecimentos de diferentes naturezas, todos necessários e indispensáveis para a atuação profissional. É mais limitada em cursos de formação inicial, e se torna mais aprofundada, diversificada e flexível a partir da experiência profissional refletida e objetivada. Portanto, se refere a um repertório profissional que contém categorias de conhecimento que subjazem à compreensão que o professor necessita para promover aprendizagens dos alunos.

Gonçalves e Gonçalves (1998, p. 109-110), apoiando-se nos estudos de Shulman, apontam características dos três tipos de conhecimento do professor (de conteúdo, pedagógico do conteúdo, e curricular). O primeiro tipo, o de conteúdo, refere-se ao específico, próprio da área de conhecimento do professor. O segundo tipo, que é o pedagógico, permite ao professor perceber quando um tópico é "mais fácil ou difícil", quais as experiências anteriores que os alunos possuem e as relações possíveis de serem estabelecidas, por isso mesmo é visto não como um conhecimento pedagógico em geral, mas um conhecimento pedagógico do conteúdo a ser ensinado. O terceiro tipo, o curricular, diz respeito ao conjunto de conteúdos a ser ensinado nos diferentes níveis e séries de escolaridade e os respectivos materiais a serem utilizados para a obtenção da aprendizagem pretendida. 
Lembremo-nos que a sala da aula não pode ser encarada como uma realidade imóvel, como se fora uma redoma apartada da sociedade. Ali, as contradições que atravessam a sociedade repercutem, de tal forma que aquilo que é produzido na sala de aula não deve ser feito somente para a sala de aula, mas essencialmente para a vida.

Nesse sentido, o percurso formativo do professor exige um processo que provoque reflexão contínua sobre a natureza, os objetivos e as lógicas que presidem a sua prática pedagógica enquanto sujeito que transforma e ao mesmo tempo é transformado pelas próprias contingências da profissão. A base de conhecimento para o ensino não é fixa e imutável. Implica construção contínua, já que muito ainda está para ser descoberto, inventado, criado.

Tal modelo foi desenvolvido considerando o conceito de ensino como profissão, envolvendo delimitação de campo de conhecimento que pode ser sistematizado e partilhado com outros. Entre as várias categorias dessa base de conhecimento, Shulman (1986) destaca: conhecimento de conteúdo específico; conhecimento pedagógico geral; conhecimento do currículo; conhecimento pedagógico do conteúdo; conhecimento dos alunos e de suas características; conhecimentos dos contextos educacionais; conhecimento dos fins, propósitos e valores educacionais. Este conjunto de categorias pode ser agrupado em: conhecimento do conteúdo específico, conhecimento pedagógico geral e conhecimento pedagógico do conteúdo.

Mas o Brasil não tem sido apenas tributário das reflexões estrangeiras. É fundamental o destaque as contribuições de Paulo Freire e seu impacto nas ideias pedagógicas contemporâneas, com repercussões no mundo inteiro. Freire delineou uma revolucionária forma de ver a educação e seus agentes, mesmo não tendo tomado a docência como ponto particular de análise. Fez incontáveis conferências para professores, escutou-os nos mais longínquos rincões da pátria e do mundo, sinalizando para a superação da racionalidade técnica na direção de um professor compromissado e 
envolvido num projeto pedagógico e político-social. Em uma das suas obras, em parceria com Ira Schor (1986), traçou elementos fundamentais para os professores entenderem melhor a construção de seus saberes profissionais. Valorizou os chamados saberes da prática, desenvolvendo a ideia de que a educação é sempre historicamente construída.

Em contribuições mais recentes Tardif $(2002,2001)$ e sua equipe ampliaram o estudo dos saberes dos professores, no intuito de compreender melhor a profissão docente. Em suas pesquisas, concluem que os saberes que servem de base para o ensino, são plurais, compostos e heterogêneos. Tais saberes, da forma como são vistos pelos professores, não se limitam a conteúdos bem circunscritos que dependeriam de um conhecimento especializado. Eles abrangem uma diversidade de objetos, de questões, de problemas que estão relacionados com seu trabalho.

Analisando a formação de um grupo de professores que formam futuros professores, Manuelli Nevenfeldt destaca a docência orientada ${ }^{4}$ como um possível caminho diferenciado e significativo neste percurso. $\mathrm{Na}$ docência orientada $\circ$ professor iniciante é acompanhado em suas atividades por um professor mais experiente, o qual servirá não só de modelo de suporte, mas fundamentalmente possibilitará a interação, o compartilhamento de ideias e de ações. Desta forma, o professor mais experiente torna-se orientador do professor iniciante, sendo responsável pelo acompanhamento das aulas e tendo a incumbência de provocar reflexões acerca das práticas desenvolvidas.

Cecília Broito (2005, p. 434) observa que a Universidad de La República (UDELAR), no Uruguai, conta com o trabalho de uma comissão setorial de ensino cuja tarefa é realizar o acompanhamento do trabalho docente. A comissão já desenvolveu diversas ações pedagógicas favorecedoras da melhoria da formação continuada do corpo docente daquela instituição.

\footnotetext{
4 A docência orientada tem caráter de disciplina na Universidade Federal de Santa Maria/RS, conforme Regimento Interno dos Programas/Cursos de Pós Graduação (Resolução 002/2001). Fonte: http://www.ufsm.br/pgfisica/docencia_orientada.html.
} 
Esta seja talvez uma ação que mereça ser efetivada em nosso país, e disseminada em nossas universidades.

O que ocorre hoje, em grande parte, é o ingresso de professores que pouco ou nada conhecem sobre a docência (principalmente quando ampliamos o seu significado). Muitos passam a conhecer um plano de aula quando descobrem que precisam apresentá-lo, como parte do ritual do processo de ingresso (especialmente nas universidades públicas, nas quais a legislação exige concurso público de provas e títulos). Passa longe da formação de grande parte dos professores universitários, conhecimentos sobre didática e metodologia de ensino, assim como das questões históricas, sociológicas, psicológicas e antropológicas que interferem nas formas de ensinar e de aprender. Não aprenderam antes, uma vez que não era da natureza dos cursos que frequentaram. Não aprendem depois quando não há uma preocupação sistematizada visando o preenchimento de tais lacunas.

\section{REPENSANDO AS PRÁTICAS}

Quando um estudante comparece a nossa frente, nem sempre paramos para pensar no significado deste ato, mas envolve uma tomada de decisão e pelo menos um objetivo. O que fazemos da nossa aula para que, ao voltar ao lar, esse estudante sinta-se contemplado? E para que nós próprios também nos sintamos? Penso que essa questão pode ser resolvida com o preparo da aula, pois ela requer começo, meio e fim. Requer atenção com a linguagem que utilizamos, de modo a não inviabilizar o entendimento, mas ao mesmo tempo não limitar o universo vocabular. Me refiro a importância de levar o estudante a conhecer os termos técnicos que são utilizados no seu campo de estudos, de perceber e entender a importância da visão de conjunto, uma vez que nenhuma profissão ou atividade esgota-se em si mesma.

A linguagem simples não significa que seja simplista. Ela busca favorecer as trocas, promover a efetiva comunicação. Não está assentada 
em rótulos e preconceitos, mas ao mesmo tempo orienta para a necessidade do aprimoramento no uso das normas que balizam a escrita, e de forma ainda mais acentuada, a escrita acadêmica.

Uma outra estória que pode servir de base para a análise de nossa ação docente tem a autoria de Max Gehringer e o título "Jesus era peripatético". É uma transcrição um pouco longa, mas creio que vale a pensa ser feita na íntegra. Vejamos:

"Numa das empresas em que trabalhei, eu fazia parte de um grupo de treinadores voluntários. Éramos coordenados pelo chefe de treinamento, o professor Lima, e tínhamos até um lema: "Para poder ensinar, antes é preciso aprender" (copiado, se bem me recordo, de uma literatura do Senai).

Um dia, nos reunimos para discutir a melhor forma de ministrar um curso para cerca de 200 funcionários. Estava claro que o método convencional -- botar todo mundo numa sala -- não iria funcionar, já que o professor insistia na necessidade da interação, impraticável com um público daquele tamanho.

Como sempre acontece nessas reuniões, a imaginação voou longe do objetivo, até que, lá pelas tantas, uma colega propôs usarmos um trecho do Sermão da Montanha como tema do evento. E o professor, que até ali estava meio quieto, respondeu de primeira.

Aliás, pensou alto:

-- Jesus era peripatético...

Seguiu-se uma constrangida troca de olhares, mas, antes que o hiato pudesse ser quebrado por alguém com coragem para retrucar a afronta, dona Dirce, a secretária, interrompeu a reunião para dizer que o gerente de RH precisava falar urgentemente com o professor.

E lá se foi ele, deixando a sala à vontade para conspirar.

-- Não sei vocês, mas eu achei esse comentário de extremo mau gosto -- disse a Laura.

-- Eu nem diria de mau gosto, Laura. Eu diria ofensivo mesmo - emendou o Jorge, para acrescentar que estava chocado, no que foi amparado por um silêncio geral.

-- Talvez o professor não queira misturar religião com treinamento -- ponderou o Sales, que era o mais ponderado de todos.

-- Mas eu até vejo uma razão para isso...

-- Que é isso, Sales? Que razão?

-- Bom, para mim, é óbvio que ele é ateu.

-- Não diga!

-- Digo. Quer dizer, é um direito dele. Mas daí a desrespeitar a religiosidade alheia...

Cheios de fúria, malhamos o professor durante uns dez minutos e, quando já o estávamos sentenciando à fogueira eterna, ele retornou.

Mas nem percebeu a hostilidade.

Já entrou falando: 
-- Então, como ia dizendo, podíamos montar várias salas separadas e colocar umas 20 pessoas em cada uma.

É verdade que cada treinador teria de repetir a mesma apresentação várias vezes, mas.... Por que vocês estão me olhando desse jeito?

-- Bom, falando em nome do grupo, professor, essa coisa aí de peripatético, veja bem....

-- Certo! Foi daí que me veio a idéia. Jesus se locomovia para fazer pregações, como os filósofos também faziam, ao orientar seus discípulos. Mas Jesus foi o Mestre dos Mestres, portanto a sugestão de usar o Sermão da Montanha foi muito feliz. Teríamos uma bela mensagem moral e o deslocamento físico... Mas que cara é essa?... Peripatético quer dizer "o que ensina caminhando".

E nós ali, encolhidos de vergonha.

Bastaria um de nós ter tido a humildade de confessar que desconhecia a palavra que o resto concordaria e tudo se resolveria com uma simples ida ao dicionário.

Isto é, para poder ensinar, antes era preciso aprender.

Finalmente, aprendemos. Duas coisas:

A primeira é: o fato de todos estarem de acordo não transforma o falso em verdadeiro. A segunda é: que a sabedoria tende a provocar discórdia, mas a ignorância é quase sempre unânime."

Penso que a narrativa acima tem relação direta com a questão da linguagem a qual me refiro como dever de ofício do docente. Não estabelecendo certo ou errado, mas utilizando termos novos e exemplificando, servindo para qualificar o debate, evitando que sejam feitas análises e até condenações tendo por suposto uma falsa interpretação de um signo linguístico.

Outro item de fundamental importância no trabalho docente é a AVALIAÇÃo. Não vou me estender sobre este tema, pois há uma rica literatura disponível, mas quero deixar claro que defendo que ela seja formativa, e explícita. É importante para quem é avaliado conhecer os critérios. E quem avalia terá melhores condições de realizar esta atividade se levar em conta os diversos fatores envolvidos no processo, portanto, entendendo que a avaliação é também parte da aprendizagem. $\bigcirc$ pior cenário é aquele em que o professor já antecipa o resultado. Partindo do pressuposto de que em uma turma há excelentes alunos, em menor quantidade, um expressivo número que fica na condição mediana, e alguns que apresentam tantas dificuldades que chegam a ser vistos como 
medíocres. Quando este olhar se instala, geralmente o resultado é a reprovação quase que antecipada de muitos estudantes que poderiam ter êxito, caso recebessem uma atenção diferenciada.

Noto que há um certo desejo no professor de encontrar estudantes atentos, dedicados, que gostem de ler e sejam capazes de entender os textos. Esse estudante dos sonhos provavelmente não teria problema com nenhum tipo de avaliação, a não ser em situações excepcionais em que dependa de uma nota oriunda da aplicação de um teste em um momento em que esteja debilitado fisicamente ou enfrentando algum trauma psicológico. Note-se que, mesmo um estudante excepcional, também pode sofrer prejuízo por conta de uma avaliação que não leve em conta o processo, o percurso formativo em todas as suas etapas. O mais grave é que não encontramos esse estudante generalizadamente nas IFES. O que temos são egressos de um sistema educacional fragilizado, muitos deles oriundos de contextos sociais extremamente desfavoráveis, famílias desestruturadas, baixos rendimentos ou até em estado de completa vulnerabilidade, ficando na dependência de políticas públicas de amparo a fim de que possam estudar, mesmo considerando o fato de estarem em uma universidade pública.

Todos estes fatores constituem desafios para a docência. Provocamnos a pensar na busca de soluções coletivas, pois não se trata de um problema isolado, em que um ou outro estudante, um ou outro professor seja afetado. Refletir sobre a nossa própria prática constitui ponto de partida para que alcancemos melhores resultados, a começar pelas nossas aulas.

\section{ALMEJANDO SER UM BOM PROFESSOR}

Hoje estamos na condição de docentes, mas para chegarmos a este ponto, tivemos uma longa trajetória discente, passando por diversas experiências formativas. Alguns são exemplos inspiradores, outros... nem tanto. Mas também com eles podemos aprender. Nesse sentido, lanço uma espécie de desafio. Use o retrovisor da vida, vasculhe o baú da memória e 
localize uma aula ou algumas aulas que se tornou ou se tornaram inesquecível(eis). Procure recordar detalhes tais como: assunto; metodologia - como foi a aula - e, principalmente, qual foi o diferencial - o que fez esta aula ser inesquecível!

A seguir, registre algumas lembranças da aula inesquecível. É um convite para refletir: A aula inesquecível para você, foi ministrada por um professor também inesquecível? Existe alguma correlação obrigatória entre estes elementos, ou é possível que comportem ocorrências isoladas? Enfim, importa mais que você possa dar atenção ao que foi marcante, considerando suas expectativas, seus objetivos, e o desdobramento daquela aula para a sua vida. Pense então no professor que conseguia ministrar as melhores aulas e tente elaborar um conjunto de características que 0 tornavam um bom professor, dividindo-as em três blocos: competência técnica; relacionamento interpessoal e atitude ética. Em seguida, procure inserir-se nestes blocos, identificando a que distância encontra-se de atingir o ponto, pelo menos mínimo desejável, para que também seja lembrado como um bom professor. Caso esse seja um desejo, uma expectativa sua. Esse exercício poderá mostrar seus pontos fortes e suas fragilidades, as quais vejo sempre como oportunidades de melhoria, de aperfeiçoamento, cujo desafio é de início, a atitude da humildade diante de outros colegas que já superaram o que para nós ainda constitui um problema, e de disposição para a troca de informações, para o diálogo permanente e ampliado, no qual a capacidade de escuta seja praticada ao máximo.

A marca essencial da docência no ensino superior é a produção de conhecimento, o desenvolvimento do saber. Seu revesso é o Adestramento e o Treinamento. Docência implica em trabalho de formação e crítica, o que inclui:

* iniciar os estudantes aos clássicos de sua área, aos problemas de sua área, e as inovações de sua área; 
* avaliar e atualizar bibliografias, recorrendo a resultados de pesquisa e aos estudos que o próprio docente tenha realizado ou esteja desenvolvendo.

* iniciar o estudante ao estilo e as técnicas do trabalho que são próprias a sua área;

* incentivar novos talentos por meio de atividades (iniciação científica, TCC) que posteriormente levarão o estudante a aprimorar-se em uma área de trabalho acadêmico, ou de pesquisa, ou por um aspecto da profissão escolhida ou ainda pelo seu lugar de trabalho político e social.

Em suma, em sua atividade docente, o professor pesquisador forma novos docentes, incentiva novos pesquisadores, prepara profissionais para atividades não acadêmicas, e ajuda a formar cidadãos. Para isso, precisa refletir sobre sua própria ação. Cuidar de seu desenvolvimento profissional. Entender-se como criador,

"Uma aranha executa operações semelhantes às do tecelão, e a abelha supera mais de um arquiteto ao construir sua colméia. Mas o que distingue o pior arquiteto da melhor abelha é que ele figura na mente sua construção antes de transformá-la em realidade. No fim do processo de trabalho aparece um resultado que já existia antes de idealmente na imaginação do trabalhador" (MARX, 1968, p. 202).

A docência não é vocação, sacerdócio e muito menos uma ação instintiva. É uma atividade profissional realizada por indivíduos concretos, em um determinado tempo e espaço que constituem um contexto que se relaciona com outros contextos, sofrendo influências externas e também com possibilidades de exercer influência, seja sobre as pessoas ou mesmo em coletivos, dado o seu potencial criativo e transformador.

\section{Considerações finais, para efeito deste artigo. Mas iniciais quanto a seu propósito}

Ao longo da exposição e também neste texto, procurei discorrer sobre situações do cotidiano, apreendidas sejam por vivência própria ou por 
relatos ou mesmo leituras realizadas com vistas a procurar entender melhor o universo do "ser professor", e sua atividade docente que na universidade vai muito além da sala de aula.

Mesmo que o professor seja oriundo de um curso de licenciatura, ou tenha tido a oportunidade de estudar disciplinas de natureza pedagógica na sua pós-graduação, dificilmente ao ingressar na docência universitária estará apto para desempenhar o conjunto de atividades requeridas que vão muito além de ministrar aulas. Na universidade a docência significa, também, entre outras coisas, a realização e a divulgação de pesquisas, a orientação de trabalhos de natureza acadêmica, a organização de eventos, a participação na gestão acadêmica com todas as atribuições técnicas e burocráticas dela decorrentes, a elaboração e a execução de projetos destinados a promover a integração da universidade com a sociedade. Consequentemente, todas estas aprendizagens precisam fazer parte do percurso formativo e do desenvolvimento profissional de um docente universitário. Por isso, a formação precisa ser continuada, coletiva e abrangente. De acordo com Pachane (2005, p. 23) a formação do docente universitário "não pode se limitar aos aspectos práticos (didáticos ou metodológicos) do fazer docente, devendo englobar as dimensões relativas às questões éticas, afetivas e político-sociais envolvidas na docência".

Finalizo a exposição e o texto renovando o desejo de boas vindas aos novos docentes da Ufopa, e reafirmando que os desafios da nossa prática docente são também oportunidades de aprimoramento. Os problemas são muitos, de vários tipos, mas nossa capacidade de enfrentamento é maior. Desde que estejamos fortalecidos pela reflexão coletiva respaldada em concepções de sociedade e de educação que orientem o desenvolvimento docente e sua intervenção na realidade, de modo a garantir a função social desta importante instituição. 


\section{REFERÊNCIAS}

BROITO, C. Pedagogia universitária: (re) visitando a assessoria pedagógica na universidade. In: MELLO, E., COSTA, F., MOREIRA, J. Pedagogia universitária: campo de conhecimento em construção. [428-447], 2005.

DEWEY, J. Como pensamos. São Paulo: Companhia Editora Nacional, 1959.

FREIRE, P.; SCHOR, I. Medo e ousadia. O cotidiano do professor. Rio de Janeiro, Paz e Terra, 1986.

GONÇALVES, T. O. GONÇALVES, T. V. Reflexões sobre uma prática docente situada: buscando novas perspectivas para a formação de professores. In: GERALDI, C. FIORENTINI, D. PEREIRA, E. (Orgs.). Cartografias do trabalho docente. Campinas: Mercado de Letras, 1998.

MASETTO, M T. Docência universitária: repensando a aula. In: TEODORO, Antônio. VASCONCELOS, M. L. (Orgs.) Ensinar e aprender no ensino superior: por uma epistemologia da curiosidade na formação universitária. 2 ed. São Paulo: Editora Mackenzie/ Cortez, 2005. [p. 79-108].

PACHANE, G. Gi. Teoria e prática na formação pedagógica do professor universitário: elementos para discussão. In: Publicatio UEPG $n^{\circ} 13$ (1) 13-24, jun. $2005 . \quad$ Disponível em http://www.revistas2.vepg.br/index.php/humanas/article/view/531

PERRENOUD, P. Práticas pedagógicas, profissão docente e formação: perspectivas sociológicas. Lisboa, Dom Quixote, 2000.

SCHON, D. Educando o profissional reflexivo. Porto Alegre, Artmed, 2000.

SHULMAN, L. S. Knowledge and teaching: foundations of the new reform. Harvard Educational Review, 1986.

SOUSA, O. C. de. Aprender e ensinar: significados e mediações. In: TEODORO, A. VASCONCELOS, M. L. (Orgs.) Ensinar e aprender no ensino superior: por uma epistemologia da curiosidade na formação universitária. 2 ed. São Paulo: Editora Mackenzie/ Cortez, 2005. [p. 35-60].

TARDIF, M.; LESSARD.; LAHYE, L. "Os professores face ao saber. Esboço de uma problemática do saber docente". Teoria e Educação, n.4, 215-233, 1991.

TARDIF, M.; RAYMOND, D. Saberes, tempo e aprendizagem do trabalho no magistério. Educação e Sociedade, Ano XXI, n. 73, dez. 2000.

TARDIF, M. Saberes docentes e formação profissional. São Paulo. Editora Cortez, 2002.

GEHRINGER, $M$. Jesus era peripatético. Disponível em: http://www.genizahvirtual.com/2013/03/jesus-era-peripatetico.html . Acesso em 15.11.2017. 